\title{
La colonización endógena: una nueva perspectiva sobre el proceso de colonización del Río de la Plata
}

\author{
Antonio Lezama Astigarraga \\ Universidad de la República, Montevideo
}

\begin{abstract}
Resumen
Este artículo parte de una serie de investigaciones de arqueología histórica realizadas desde 1993 en la región de Colonia del Sacramento. La aparición de cerámica de diversos orígenes, cuya presencia no se esperaba, ha llevado al autor a profundizar el tema de la colonización del Río de la Plata. Contrariamente a la versión tradicional de la historiografía hispanoamericana, se argumenta que fue un proceso esencialmente americano, impulsado por los intereses de los mineros de la plata de Potosí, que se desarrolló a partir del fracaso de la expedición de Pedro de Mendoza y fue ejecutado por los hijos y nietos de los conquistadores del Perú y de los fundadores de Asunción.
\end{abstract}

\begin{abstract}
Abstratc
Este artículo parte de una serie de investigaciones de arqueología histórica realizadas desde 1993 en la región de Colonia del Sacramento. La aparición de cerámica de diversos orígenes, cuya presencia no se esperaba, ha llevado al autor a profundizar el tema de la colonización del Río de la Plata. Contrariamente a la versión tradicional de la historiografía hispanoamericana, se argumenta que fue un proceso esencialmente americano, impulsado por los intereses de los mineros de la plata de Potosí, que se desarrolló a partir del fracaso de la expedición de Pedro de Mendoza y fue ejecutado por los hijos y nietos de los conquistadores del Perú y de los fundadores de Asunción.
\end{abstract}

Este trabajo fue presentado por primera vez, bajo el título "Raíces coloniales del puente Colonia-Buenos Aires," en la mesa redonda "O povoamento da Bacia do Prata," del III Congreso Internacional de Estudios Ibero-Americanos, PUCRS, Porto Alegre, 20 de agosto 1998. Una versión previa ha sido publicada en Arno Alvarez Kern, ed., Sociedades Ibero-Americanas, Reflexoes e Pesquisas Recentes (EDIPUCRS, 2000), 317-46, y en Cuadernos del CLAEH, nos. 83-4, 2a ser. (1999): 7-28. El autor es Profesor Adjunto del Departamento de Arqueología de la Facultad de Humanidades y Ciencias de la Educación de la Universidad de la República, Montevideo; Doctorado en Arqueología en la École des Hautes Études en Sciences Sociales, París, 1983. 


\section{Introducción}

Las investigaciones de arqueología histórica que desde 1993 venimos realizando en la región de Colonia del Sacramento en el marco del impacto que podría causar la construcción del puente entre las ciudades de Colonia (ROU) y Buenos Aires (Argentina) han llevado a profundizar permanentemente sobre el tema de la colonización del Río de la Plata con el fin de disponer de una adecuada base teórica para la interpretación de los vestigios arqueológicos que se fueron encontrando en general y, en particular, la -para nosotros- sorprendente presencia de cerámica indígena y/o "mestiza" en contextos del último cuarto del siglo XVIII.

Dicha investigación histórica obligó a remontarse a los inicios del proceso donde se constató que el proceso de colonización del Río de la Plata, contrariamente a la versión tradicional de la historiografía hispanoamericana, fue en realidad un proceso esencialmente americano -fracasada la pomposa expedición de Pedro de Mendozaorquestado desde la entraña platina del Potosí, ejecutado por los "mancebos de la tierra," hijos y nietos de los conquistadores del Perú y de los supervivientes fundadores de Asunción. ${ }^{1}$

De esta constatación se desprendían dos consecuencias de interés fundamental. Por un lado, que si esta colonización era obra de las primeras generaciones de criollos era en realidad y necesariamente una colonización realizada por mestizos, y por otro lado, que el verdadero motor del proceso y la base de su éxito y permanencia, era la evacuación, por la vía técnicamente más apropiada -estando Potosí en la misma cuenca del Plata- del torrente de plata que allí se producía ${ }^{2}$ y no la apropiación inorgánica e innecesaria de territorios entonces improductivos.

Con relación al primer aspecto se señala que los ejecutores de la colonización son los hijos de las "Ñustas" andinas o de las "Chinas"3 guaraníes y que su visión de los

\footnotetext{
${ }^{1}$ Es de destacar que esta población original es todo menos homogénea, como formada por los tan diversos súbditos del emperador Carlos V. En la expedición de Mendoza por ejemplo "abundaban, por licencia especial, los extranjeros: alemanes, ingleses, italianos, portugueses, flamencos." Paul Groussac, Mendoza y Garay, (1916; Buenos Aires: Academia Argentina de Letras, 1949), 1:105.

${ }^{2}$ Según Ricardo Levene, Investigaciones acerca de la historia económica del Virreinato del Plata, vol. 1 (La Plata, 1927), 117, en 40 años se arrancaron del Cerro de Potosí 111 millones de pesos ensayados.

${ }^{3}$ Ambas son voces quechuas, "Ñusta" equivale a noble y "China" a mujer del pueblo. Esta última voz se utilizó como sinónimo de mujer en el lenguaje rioplatense. Ver Daniel Granada, Vocabulario rioplatense
} 
problemas, con relación al territorio, a las culturas indígenas, a las prácticas económicas, etc., no es uniforme, ni la del "otro," que tiene profundas raíces prehistóricas que sin duda condicionan muchos aspectos de su comportamiento.

Con relación al segundo aspecto se abre un tema de enormes derivaciones históricas, que finalmente nos conectan con la problemática actual del puente Colonia-Buenos Aires, ya que el éxito de la empresa potosina-platense se debió a la genial creación en 1585 por parte del entonces obispo de Tucumán, Fray Francisco Vitoria, ${ }^{5}$ de un "puente" con la colonización portuguesa del Brasil, en particular con su expresión más criolla (y también mestiza) de São Paulo, cerrando un circuito en el cual se intercambiarán por dos siglos, plata por mercaderías.

La historia de la colonización del Río de la Plata es en sus primeros dos siglos, la historia de la supervivencia de dicho "puente" y sus avatares -como la Colonia del Sacramento- en torno a la cual se consolida la ocupación del territorio uruguayo y riograndense, y la desde entonces preponderancia económica de centros como Buenos Aires y San Pablo.

En esta presentación se considerarán las principales líneas de fundamentación de ambas afirmaciones, explorando sus consecuencias y derivaciones en la organización y las características de la naciente sociedad rioplatense.

razonado (1889; Montevideo, 1957); Juan Grau, Voces indígenas de uso común en Chile (Santiago: Oikos, 1997); y Juan Carlos Guarneri, Nuevo vocabulario campesino rioplatense (Montevideo, 1957).

${ }^{4}$ Ver por ejemplo, Gustavo Verdesio, La invención del Uruguay: La entrada del territorio y sus habitantes a la cultura occidental (Montevideo: Graffiti, 1996), en relación a esta postura que plantea el sostenido desconocimiento del "otro."

5"El, obispo de tuquman don fray françisco de vitoria a sido el primero que armo vn navio y partio deste puerto el año 86 , para el brasil con çierta plata labrada y con ella compraron, otro de que venian dos navios con aquel enpleo de cosas de azucares y conservas y algunas mercaderias para aquella governacçion y para potosy..." “... por la via del, obispo, torna agora a enviar el uno de los navios, al brasil quedaron movidos, otros navios para venir en bolviendo estos para tener trato con el piru y tuquman que de, oy en adelante confio en nuestro señor que tendra vuestra magestad aprovechamientos en almoxarifazgos." Párrafos de la relación de los principales sucesos del Río de la Plata por el tesorero Hernando de Montalvo, documento 17, Buenos Aires, 23 de agosto 1587, Historia de los piratas en el Río de la Plata, ed. Enrique De Gandia, (Buenos Aires, 1936), 255. Ver también Raúl A. Molina, Las primeras experiencias comerciales del Plata: El comercio marítimo 1580-1700 (Buenos Aires, 1966), 25. 


\section{Arqueología e historia}

Estos apuntes surgen como complemento necesario de las investigaciones de arqueología histórica que venimos adelantando en el área rural de Colonia del Sacramento. Los trabajos arqueológicos se desarrollan siempre en un marco interpretativo, muchas veces llamado "marco teórico," que no es más que la base de conocimientos adquiridos previamente sobre la temática que vamos a investigar. En el caso de la "Arqueología Histórica" este marco está dado principalmente por el conocimiento histórico que se tenga sobre el área investigada. Sin embargo no debe pensarse que el arqueólogo trabaja para confirmar los datos de la Historia, sino que lo que pretende hacer es abrir el espectro de los puntos de vista posibles, agregando a la documentación escrita la información que proviene del análisis de los vestigios materiales.

Sin entrar, todavía, a discutir la variada naturaleza del llamado conocimiento histórico, dividido por corrientes interpretativas, focos de interés, etc., como cualquier ciencia social, es indudable que dicho conocimiento va dibujando un telón de fondo sobre el cual el arqueólogo va colocando sus propias piezas.

Cuando comenzamos con esta investigación el marco de referencia casi exclusivo con el que contábamos era el de la disputa entre Portugal y España por el control del área. ${ }^{6}$ Esto traería como consecuencia arqueológica -por ejemplo- que en algunos sitios localizaríamos materiales "portugueses" y en otros, materiales "españoles." A poco de empezar a trabajar nos dimos cuenta que, en aquellos lugares con cerámica que podía servirnos como indicador de referencia cultural, esta era siempre "portuguesa" mientras que por otro lado, aún en contextos tardíos del siglo XVIII, teníamos presencia de cerámica indígena o "mestiza" que no es ni "portuguesa" ni "española" y que no figuraba en nuestro "marco teórico."

\footnotetext{
${ }^{6}$ Ver por ejemplo Aníbal Riveros Tula, Historia de la Colonia del Sacramento (Montevideo, 1959).

7 Antonio Lezama, "Informe sobre los sitios históricos," en Relevamiento arqueológico del área a ser afectada por la construcción del puente Colonia-Buenos Aires (Montevideo: Universidad de la República, Departamento de Arqueología, 1993), 21-85; Idem, Arqueología histórica de salvamento en el entorno rural de Colonia de Sacramento (Montevideo: Universidad de la República, Departamento de Arqueología, 1995).
} 
Nos hemos visto pues obligados a aguzar nuestro conocimiento histórico buscando aquellos elementos que nos permitieran comprender mejor la realidad arqueológica que encontrábamos. Esta nueva búsqueda nos demostró, una vez más, que, pese a que los arqueólogos escribimos para los historiadores, la recíproca no se cumple y que, cuando uno quiere ir al conocimiento de los hábitos en el uso de la cultura material, terreno en el que juega el arqueólogo, la información disponible es desesperantemente escasa y uno se ve obligado a reescribir su propia historia ad-hoc.

De eso se trata en estas páginas, de la búsqueda del tratar de entender, en la documentación histórica, cuál era la naturaleza verdadera del "portugués" y del "español" que actuaron en este escenario, de explicar qué significaron dichos términos en aquel contexto, que engloba y que escapa a ellos, estableciendo claves de mayor utilidad a la hora de la interpretación arqueológica. ¿Era el indio guaraní misionero, español? ¿Era el desertor, viviendo en las tolderías guenoas, portugués? ¿Era el "gaucho" criollo-portugués, criollo-español, guaraní-criollo, tupí-criollo, negro-criollo, portugués o español? ¿Por qué vivimos en un país de toponimia guaraní y vocabulario quechua?

La historiografía tradicional hispanoamericana que conocemos (la lusobrasileña tiene un enfoque completamente distinto del proceso $)^{9}$ es de un reduccionismo absoluto con relación a la colonización del Río de la Plata y a la Colonia del Sacramento, a tal punto que prácticamente borra la esencia de los acontecimientos desarrollados durante casi tres siglos. Los elementos esenciales de esa reducción son:

- que la colonización es un proceso europeo en el sentido que fue realizado desde Europa y para Europa;

- que fue un proceso tardío, fracasada la búsqueda de metales preciosos;

- que se vio lenta pero progresivamente estimulado por el reconocimiento de las bondades naturales de la región, en particular su productividad pecuaria;

- que este potencial despertó el interés de Portugal que "vio" en el Río de la Plata un "límite natural" a su expansión territorial hacia el Sur y

\footnotetext{
${ }^{8}$ Ver nota 1 .

${ }^{9}$ Ver por ejemplo, Luís Ferrand de Almeida, "A Colónia do Sacramento e a Formação do Sul do Brasil," en Páginas dispersas: Estudos de história moderna de Portugal (Coimbra: Universidade de Coimbra, Faculdade de Letras, 1995); o Fernando Camargo, Britânicos no Prata, Caminhos da Hegemonia (Passo Fundo: Universitária, 1996).
} 
- que la rigidez del sistema monopolista español creó un ambiente propicio para el desarrollo del contrabando.

En esencia, "españoles" indolentes vegetan a orillas del Plata hasta que la crianza de ganados se vuelve substantiva mientras que "portugueses" -siempre expansionistas, no se sabe por qué causas- insomnes trabajan desesperadamente por llevar sus fronteras al límite que la naturaleza les predestinó. Colonia del Sacramento es la culminación del proceso, con el difícil despertar "español" procurando alejar a su rival y quimérica tentativa "portuguesa" que igual logra "mover" su frontera hasta la laguna Merín. El cuadro es jalonado por enfrentamientos bélicos y acontecimientos diplomáticos, con una escasa valoración de los aspectos económicos los que son valorizados "a futuro," si se admite la expresión, y alguna mención marginal sobre el soporte demográfico de estos episodios. La Historia del Río de la Plata todavía está incubándose y recién se comenzará a manifestar a partir de las invasiones inglesas. ${ }^{10}$

Mucho más finos eran sin duda los hilos de la urdimbre del tejido histórico con el que pretendíamos desentrañar su reflejo arqueológico. Hacia su búsqueda nos tuvimos que dirigir entonces para tratar de entender cómo se generó, conceptual y físicamente este espacio de "frontera" entre lo colonizado y lo "salvaje," entre lo "portugués" y lo "español," entre lo "lícito" y lo "ilícito", una frontera aparentemente más allá del mundo contemporáneo $\mathrm{y}$, sin embargo, pieza clave en las mesas de negociaciones internacionales.

Esto para tratar de entender las diferentes vertientes del fenómeno "mestizo," la sangre, la cultura, las ambiciones, las lenguas y las comidas "mestizas" entre otras; para tratar de entender un mundo definido por las indefiniciones, un mundo que impone el arbitraje permanente entre la legalidad corrompida y la corrupción legalizada, entre el juicio y la impunidad, entre la fortuna y la miseria entre las jerarquías y la anarquía, entre éxitos asombrosos y fracasos rotundos, entre desiertos edénicos y civilizaciones miserables, entre distancias asombrosas y circulaciones permanentes.

Recién, cuando esbocemos este cuadro tendríamos las referencias suficientes para intentar la lectura de los hechos arqueológicos que vamos generando.

\footnotetext{
${ }^{10}$ Sin perjuicio de que la última publicación uruguaya que conocemos sobre el tema, Fernando Assunçao, "Historia," en Colonia del Sacramento: Patrimonio histórico de la humanidad (Montevideo: UNESCO, 1996), expone muchos de los conceptos que proponemos aquí.
} 


\section{La colonización del Río de la Plata}

El proceso de colonización del Río de la Plata ha sido normalmente interpretado como la apropiación del territorio por parte del europeo, que exterminó, alejó o integró por la fuerza a las culturas nativas. En este esquema, la cultura invasora ignora al "otro," construyendo su propia visión del territorio y sus posibilidades en función de parámetros exclusivamente occidentales. ${ }^{11}$ El corolario de esta interpretación es que la nueva realidad cultural que va surgiendo tiene muy cortas raíces y la misma resulta de la importación y rápida -aunque a menudo imperfecta- adaptación de prácticas europeas, de influencia española o portuguesa, a las que se agrega marginalmente un componente africano.

En particular, la historiografía referente a la Colonia del Sacramento ha tradicionalmente interpretado su historia como las vicisitudes de una cabecera de puente de las pretensiones territoriales portuguesas enfrentada a las "legítimas" reacciones castellanas, haciendo remontar su origen a los problemas de interpretación del Tratado de Tordesillas. $^{12}$

Sin embargo, el famoso tratado de Tordesillas, y las "ambiciones territoriales" de Portugal, muy poco tuvieron que ver con la fundación de Colonia del Sacramento y su tormentosa historia. Fue en realidad el resultado de una audaz propuesta comercial, que, partiendo de intrincados lazos -en particular familiares ${ }^{13}$ - entre los pobladores de Asunción y del Tucumán, buscó la salida "natural" de la catarata de plata que acababa de abrirse en Potosí. ${ }^{14}$

\footnotetext{
${ }^{11}$ Ver nota 3.

${ }^{12}$ Ver Luis Enrique Azarola Gil, La epopeya de Manuel Lobo: Contribución a la historia de Colonia del Sacramento seguida de una crónica de los sucesos desde 1680 hasta 1828 y de una recopilación de documentos (Madrid, 1931); y Riveros, Historia de la Colonia.

${ }^{13}$ Ver Groussac, Mendoza y Garay, 2:102.

${ }^{14}$ Según datos tradicionales que no hemos podido confirmar se habrían extraído unos 20 millones de kilos de plata hasta fines del siglo XVIII.
} 
Este intento, primero público y legal, incluso defendido con argumentos frente a la corona Castellana, ${ }^{15}$ puso en marcha los mecanismos del mercado, cuyas reglas sólo tienen en cuenta el riesgo y la ganancia esperada, generando una realidad comercial, que hizo posible la incipiente existencia del -ya una vez abandonado ${ }^{16}$ - puerto de Buenos Aires, sin otros recursos a su disposición ni económicos ni demográficos y la prosperidad del comercio de los puertos del Brasil, beneficiados por la circunstancial unión de las coronas Castellana y Portuguesa en la figura de Felipe II.

Esta realidad, generó una corriente económica, desde el Alto Perú hasta Bahía, pasando por San Pablo, mediante la cual la plata se intercambiaba por mercancías y bienes de consumo, en particular el azúcar, que dinamizaba ambas economías y volvió posible la permanencia y el crecimiento de Buenos Aires, en la cual se instaló un importante núcleo de comerciantes portugueses, muchos de ellos judíos conversos de origen español que se fueron convirtiendo en uno de los pilares de la naciente sociedad porteña. ${ }^{17}$

La conciencia que la administración castellana fue cobrando de la importancia de la fuga de metal precioso que significaba este comercio y la obtusa visión monopólica de la misma fueron acotando en la ilegalidad un desarrollo económico inexorable. La separación de las coronas agravará esta situación y es entonces que surge la idea de fundar una factoría portuguesa, como única posibilidad de mantener abierta esa corriente comercial que era la vida y razón de ser del puerto de Buenos Aires. ${ }^{18}$

\footnotetext{
${ }^{15}$ Ver por ejemplo, Memorial del Licenciado Antonio Fernández de Castro, presentado al Consejo, acerca de las fortificaciones del puerto de Buenos Aires, y sobre la conveniencia de cambiar los frutos de las provincias del Río de la Plata en el Brasil, documento 28, Historia de los piratas, 299. En el "50 punto" de este documento afirma que la mejor defensa de Buenos Aires es permitirle el comercio y aclara: "Ponense dos objeçiones a esto. La 1. ${ }^{\mathrm{a}}$ que dando liçençia a los de buenos ayres para que saquen los frutos de la tierra al brasil se hara mucho daño a la contrataçion de Seuilla y tierra firme. La 2. ${ }^{\text {a }}$ que si se da la dicha liçençia con limitazion la tomaran sin ella y con esto acudiría toda la gente de Potossi, Tucuman, y Chile a este puerto por ser tan acomodado para traer mercaderias de Hespaña." Rechaza el argumento de la competencia con Sevilla pues dice que no llega ninguna mercancía por la vía de Lima hasta Buenos Aires por el costo del flete.

${ }^{16}$ Sobre las causas de su fracaso inicial y del éxito de su segunda fundación ver en particular Roberto Levillier, "Conquista y organización del Tucumán," en Historia de la nación argentina, ed. Ricardo Levene, 2a ed., vol. 3 (Buenos Aires: Ateneo, 1939), 275; sobre el fracaso de la expedición de Mendoza ver Groussac, Mendoza y Garay, 1:172, 174, 195, 214, 228.

${ }^{17}$ Ver por ejemplo, Molina, primeras experiencias comerciales, 48, 61; y José Torre Revello, "La Colonia del Sacramento," en Historia de la nación argentina, 343.

${ }^{18}$ Ver Ferrand de Almeida, "Colónia do Sacramento," 166.
} 
Serán entonces los intereses porteño-brasileños los que, mediante presiones en el Consejo Ultramarino, conseguirán finalmente la empresa de Manuel Lobo y gracias a esta, durante casi 100 años mantendrán con altibajos esa dinámica comercial.

Es interesante ver cómo no se ha resaltado suficientemente la continuidad histórica, incluso la "inmediatez" cronológica de todo el proceso de colonización de la cuenca del Plata. La misma se hizo pensando que era la ruta para llegar a la plata, sin ninguna otra consideración y por lo tanto groseramente improvisada. Cuando efectivamente la plata surgió en el Potosí (que se encuentra en la propia cuenca del Plata) aún continuaba el proceso de colonización original ahora a partir de Asunción y, lógicamente se continúo y consolidó la idea, ahora en competencia con el Perú, ${ }^{19}$ de que el metal debía salir por el Plata. Por otra parte, desde la primer fundación de Buenos Aires, las bases inmediatas de apoyo, los contactos más fáciles se encuentran en la costa del Brasil portugués ${ }^{20} \mathrm{y}$ hacia ellas -o por ellas- tenderá lógicamente a pasar el nuevo flujo creado.

Es como si en el discurso histórico se cortara la realidad "psicológica" (como motivación de los conquistadores-colonizadores), la que sólo "actúa" al inicio de la conquista, para pensar inmediatamente a la geografía en sus términos actuales, aislando como realidades políticas el Alto Perú, Asunción, Tucumán, Buenos Aires y las ciudades de la costa del Brasil, como circuitos independientes, cuando aún están concebidos como una única realidad conquistadora-colonizadora.

En este marco la llamada "colonización europea del Río de la Plata," contrariamente a las versiones más difundidas, es esencialmente un fenómeno americano, en el que participan principalmente los criollos de las primeras generaciones, por lo tanto mestizos, los que a través de sus madres y tíos indígenas se engarzan asimismo con profundas tendencias prehistóricas.

La presencia europea genera el marco en el que se resolverá la acción individual de personas cuyo sino es americano. Estos se reclaman de sus reyes, por herencia paterna y

\footnotetext{
${ }^{19}$ En relación a la competencia Asunción vs. Alto Perú ver Levillier, “Conquista y organización,” 243.

${ }^{20}$ La expedición de Mendoza ya trae consigo a Gonzalo de Acosta, "antiguo vecino de San Vicente," (¿náufrago o desertor de Gaboto?), portugués, que tenía hijos nacidos en Santa Catalina (viviendo con los Indios durante 20 años) que venía como práctico y "lengua." (Groussac, Mendoza y Garay, 1:104, 160, 183). Assunçao, en "Historia," aporta interesantes datos sobre el origen de San Vicente y sus relaciones con Asunción.
} 
por ser en última instancia la garantía de su poder y posición social, pero tienen en la realidad una praxis opuesta a los designios gubernamentales ciegamente basados en la voracidad fiscal que remedie la permanente bancarrota de las cortes europeas.

El tema central es entonces que en el Río de la Plata no hubo una nítida frontera entre lo europeo transplantado y lo indígena, sino que, desde el comienzo de su colonización, se generaron y regeneraron una gran diversidad de "fronteras," entre diferentes "mundos" o "complejos culturales." El "mundo" Inca, el "mundo" Coya, el "mundo" Guaraní, el "mundo" Guaycurú, el "mundo" Charrúa, el "mundo" Minuán, el "mundo" de Lima, el "mundo" de Charcas, ${ }^{21}$ el "mundo" de Potosí, el "mundo" de Santa Cruz, el "mundo" de Tucumán, el "mundo" de Chile, el "mundo" de Córdoba, el "mundo" de Asunción, el "mundo" de Santa Fe, el "mundo" de Buenos Aires, el "mundo" de Colonia del Sacramento, el "mundo" de São Paulo, el "mundo" de Río de Janeiro, el "mundo" de Bahía, el "mundo" de Montevideo, el "mundo" de Angola, el "mundo" Jesuita, el "mundo" Español y el "mundo" Portugués, entre otros, que buscarán en la cuenca del Plata, en mayor o menor medida la solución a sus destinos individuales, generando las particulares características de su proceso colonial.

La clave de estos encuentros, las causas y mecanismos de las distintas conductas, sus engarces y resultantes, las consecuencias futuras de estas dinámicas recién empiezan a dibujarse imperfectamente en las referencias cronológicas y geográficas que hemos encontrado y que desarrollaremos en las próximas páginas.

\section{A. La colonización inicial europea y su fracaso (hasta el "desencanto" de la tierra)}

La expedición de Pedro de Mendoza (1536) se enmarca dentro de la aceleración que sufre el proceso de colonización de América como consecuencia del impacto causado por la llegada a España de los tesoros de México y del Perú. ${ }^{22}$ Las riquezas metálicas de América parecen infinitas y el entusiasmo se apodera de la, hasta entonces, poco motivada nobleza española.

\footnotetext{
${ }^{21}$ Charcas, La Plata y Chuquisaca, actualmente Sucre, son la misma ciudad fundada en 1538. Ésta fue fundada con el nombre de La Plata, en la provincia de Charcas de donde tomará nombre la audiencia que reside en La Plata.

${ }^{22}$ Ver Enrique De Gandia, "La segunda fundación de Buenos Aires," en Historia de la nación argentina, 144.
} 
Es así que la expedición de Mendoza, gestada al mismo tiempo que la llegada de los tesoros acumulados por Pizarro (1534), es la más importante de todas las enviadas a América, tanto por la "calidad" de los participantes como por su número y pertrechos. ${ }^{23}$

Las débiles indicaciones recogidas en las expediciones de Solís (1516), Magallanes (1519), Gaboto y Diego García (1526) ya se habían transformado, en el contexto de la época, en el "Río de la Plata," la vía de entrada al país del "Rey Blanco" (de plata), garantizando el éxito de los participantes en la empresa. De este modo se organiza una verdadera expedición de saqueo, en que lo militar es lo básico, que llega al colmo de no traer ni herramientas de labranza ni animales de granja. ${ }^{24}$

El fracaso es casi total y absoluto ${ }^{25}$ (no es del caso entrar en detalles ahora, pero hay que tener en cuenta, para entender la dinámica posterior, que uno de los territorios más fértiles del mundo es considerado como totalmente miserable e improductivo por estos primeros colonos), quedando reducida una expedición de 1,200 hombres, a 5 años de comenzada, a los aproximadamente 400 colonos que se instalan en Asunción (1537), gracias a su alianza con los Carios (Guaraníes).

Tenemos entonces que el primer capítulo exitoso de la colonización de la cuenca del Plata sucede como consecuencia de la mezcla entre los intereses europeos y los del "otro," del indio americano. Señalemos sólo algunos rasgos que creemos trascendentes. Los Guaraníes ofrecen a los Castellanos su alianza estratégica, no son "conquistados" por estos. Por eso ofrecen a sus hermanas e hijas en matrimonio, para asegurar la alianza con los lazos del parentesco. ${ }^{26}$ Así comienzan a nacer (estamos en 1537) los "mancebos de la tierra," "españoles" en la consideración legal, guaraníes por sus madres y sus tíos, que en sólo 20 años comenzarán a ser los protagonistas de los acontecimientos regionales.

Esta alianza tiene raíces indias y raíces europeas. Los guaraníes buscan asegurarse la supremacía militar con las armas y caballos que aportan los castellanos principalmente contra el invicto enemigo Guaycurú, azote de sus fronteras. Los castellanos proponen llegar al Paitití -el reino blanco-, cuyas fronteras se han extendido hasta los territorios de sus parientes chiriguanos, los que, por intercambio o rapiña, han conseguido las

\footnotetext{
${ }^{23}$ Ver Groussac, Mendoza y Garay, 1:103.

${ }^{24}$ Ibid., 1:107.

${ }^{25}$ Buenos Aires es definitivamente abandonada en 1541.

${ }^{26}$ Efraim Cardozo, “Asunción del Paraguay,” en Historia de la nación argentina, 178.
} 
muestras de plata que, a miles de kilómetros de distancia, propiciaron la empresa castellana.

Durante los próximos 24 años la nueva sociedad asunceña buscará sola, en una casi absoluta incomunicación con la metrópoli, ${ }^{27}$ hacia el noroeste como indican sus socios, el camino a las montañas de la plata, enfrentando la mayor o menor oposición de las tribus indígenas hasta encontrarse en 1561, en el futuro emplazamiento de Santa Cruz de la sierra, con la expedición castellano-andina que "bajaba" del Perú. El resultado de la empresa asunceña será, en la pintoresca y angustiada expresión de Ñuflo de Chaves el "desencantamiento" de la tierra, la pérdida de una ilusión que durante 22 años mantuvo vivo el espíritu de la conquista. ${ }^{28}$

La depresión de la "gens" asunceña se evidencia en la casi despoblación de la localidad, que queda casi reducida a los ancianos e impedidos, abandonada por la población activa de origen castellano que resuelve emigrar hacia el Perú. ${ }^{29}$

\section{B. La colonización del "Alto Perú" y la búsqueda de las "puertas" de la tierra}

Al mismo tiempo que se desarrollan estos acontecimientos en la cuenca del Plata (entre 1536 y 1560), se desarrolla la colonización del Perú y zonas circundantes, en particular Chile y el "Alto Perú."

Esta colonización está signada por una permanente anarquía, marcada por una feroz disputa entre intereses individuales de todo signo y origen, privados, estatales, religiosos y étnicos de importante trascendencia para el futuro proceso de la cuenca del Plata. ${ }^{30}$

No es probable que los futuros protagonistas de la segunda etapa de la colonización del Río de la Plata, no hayan sido marcados en su conducta por su participación en estos acontecimientos. Estos supusieron un singular ejercicio de lealtades personales (particularmente en lo que a deslealtad se refiere), de sometimiento a las estructuras

\footnotetext{
${ }^{27}$ El único contacto importante es la llegada -por vía terrestre- del $2^{\circ}$ adelantado Cabeza de Vaca en 1542. Llegan a pasar períodos de 6 años sin que haya ningún contacto directo con la metrópoli. Groussac, Mendoza y Garay, 2:100.

${ }^{28}$ Ibid., 2:92.

${ }^{29}$ Cardozo, "Asunción del Paraguay," 187.

${ }^{30}$ Ver, entre otras, la exhaustiva obra de Albert Garcia, La découverte et la conquête du Pérou d'après les sources originales (París: Klincksieck, 1975).
} 
estatales (sobre todo en lo que a su desconocimiento o insubordinación se refiere) que va a generar actores entrenados en caminar por la cuerda floja del que acata pero no cumple, del que acepta pero desconoce, del que jura y abjura, en definitiva, del que logra asegurar sus propios intereses contra la codicia de todos, empezando por el lejano monarca y sus delegados locales.

Desde el punto de vista del futuro rioplatense el momento trascendente de este proceso es el descubrimiento -en 1545, tan sólo 13 años después de comenzado el proceso de conquista- del más rico yacimiento de plata jamás encontrado, en el cerro de Potosí, equidistante de Lima y de Buenos Aires, en las nacientes del Pilcomayo, en la propia cuenca del Plata.

Este descubrimiento se realiza a partir de la colonización de las regiones marginales del área Coya del Incario, con la fundación de "La Plata." 31 Son estos los tiempos de la represión contra los encomenderos pizarristas y de la intervención del "Presidente" La Gasca (1546-1550). Tiempos que suponen vertiginosos enriquecimientos si con habilidad política se logra el apoyo del vencedor.

En ese contexto los Ortiz de Zárate y sus parientes se hacen dueños de los principales filones del Potosí, ${ }^{32}$ junto a otras inmensas riquezas y desde 1556 , por lo menos, ${ }^{33}$ comienzan a buscar una salida más barata a la creciente producción de plata. ${ }^{34}$ Este propósito que se llamó gráficamente buscarle "puertas a la tierra"35 absorberá durante décadas ingentes esfuerzos por parte de las poblaciones altoperuanas. ${ }^{36}$

\footnotetext{
${ }^{31}$ Ver nota 20.

${ }^{32}$ Uno de los propietarios de la veta "Rica" era Juan Ortiz de Zárate, quien, además, tenía parte en la "Mendieta," cuyo descubridor y primer propietario era su hermano mayor, Lope de Mendieta, el millonario de la familia. Groussac, Mendoza y Garay, 2:61.

${ }^{33}$ En 1556 ya estaba planteada la candidatura de Ortiz de Zárate, apoyada por -entre otros- Juan de Matienzo (oidor en Charcas) quien escribe al rey: "los muchos y grandes provechos que se seguirán deste puerto demás de lo que tengo dicho, irá a vuestra magestad el capitan juan ortíz de çarate portador desta a quien puede vuestra magestad dar crédito cerca desto por ser tan antiguo en la tierra." Tomado de De Gandia, "La segunda fundación," 210; éste trae en las páginas 206-10 otros antecedentes al respecto.

${ }^{34}$ En 1558 Potosí ya tiene 160,000 habitantes y es una de las ciudades más grandes del mundo.

${ }^{35}$ Ver De Gandia, "La segunda fundación,” 218; y Cardozo, “Asunción del Paraguay,” 184.

${ }^{36}$ Numerosas "entradas" se realizan desde el Alto Perú con el propósito de abrir la ruta hacia el Atlántico; después de numerosos fracasos debidos fundamentalmente a la oposición de las poblaciones indígenas, se logra establecer la ruta en forma definitiva. Es ilustrativa la cronología de las fundaciones exitosas: Santiago del Estero en 1553, Santa Cruz en 1560, Tucumán en 1565, Córdoba y Santa Fe en 1573 y, luego de la segunda fundación de Buenos Aires, La Rioja en 1591, Madrid en 1592 y Jujuy en 1593.
} 
El elemento humano protagonista de esta empresa será cada vez más "americano." Es al principio el conquistador español y su aliado indio con sus propias motivaciones. ${ }^{37}$ Son luego los mismos conquistadores, pero ahora transformados en propietarios con intereses en América y no en España, acompañados de sus hijos mestizos, hijos de las "Ñustas," las princesas del Incario. ${ }^{38}$ Al mismo tiempo las poblaciones indígenas originales están cada vez más afectadas por las nuevas modalidades económicas y las presiones culturales que las obligan a un proceso de readecuación de sus comportamientos políticos. ${ }^{39}$ Son finalmente los descendientes de los conquistadores (en su mayoría mestizos) acompañados por nuevos inmigrantes europeos que deben ajustar sus expectativas a una "situación de hecho" donde las principales riquezas ya están repartidas y donde sus aspiraciones deben encauzarse dentro de las sendas trazadas por los detentores del poder económico y/o político.

\section{La "puerta de la tierra," primera etapa hasta 1641}

Con el encuentro de 1559, quedan perdidas las esperanzas protagónicas de Asunción pero se confirma el deseo de los potosinos. A partir de ese momento, y bajo el impulso de Ortiz de Zárate se acelera el proceso que culminará con la refundación de Buenos Aires, que resultará la tan ansiada "puerta de la tierra."

La fundación de Buenos Aires será obra, casi exclusivamente, de los "mancebos de la tierra," en su mayoría nacidos en Asunción. El capitán español, Juan de Garay, factótum de Ortiz de Zárate, había llegado en 1544 al Perú con sólo 14 años y en 1560 participa de la fundación de Santa Cruz, donde se emparentará con la población de Asunción. Estos "mancebos" le imprimen un sello particular a la empresa porque ellos son, al decir

\footnotetext{
${ }^{37}$ Dejamos aquí planteado el tema de las problemáticas prehistóricas de las poblaciones indígenas que se continúan durante la conquista y que muchas veces fueron claves para su relación con los conquistadores; ¿Cuál era, por ejemplo, la situación de los "coyas" dentro del Tahuantinsuyo y las oposiciones y solidaridades que de ésta se derivan? Hay que pensar también las difíciles relaciones de estas poblaciones con sus vecinos Chiriguanos y Calchaquíes, incluso la posible existencia de un "limes" inca en esta frontera.

${ }^{38}$ La hija de Ortiz de Zárate, heredera de sus capitulaciones como "Adelantado" es hija de una Ñusta. De los 84 hombres que acompañan a Garay en la fundación de Santa Fe, 75 son "mancebos de la tierra." Siete años después cuando vuelve a fundar Buenos Aires, de 60 fundadores, sólo 10 son nacidos en España. Groussac, Mendoza y Garay, 2:146, 275; y Cardozo, “Asunción del Paraguay,” 189, 193.

${ }^{39}$ Por ejemplo con la institución de la "mita" minera y los comportamientos que engendra para tratar de alejarse, física o socialmente, de las zonas de reclutamiento.
} 
del contador Montalvo "amigos de cosas nuevas" pero totalmente desestimulados en cuanto a la búsqueda de la acumulación de riquezas en base al trabajo productivo. ${ }^{40}$ Probablemente porque, durante toda su existencia, estuvieron alejados de todo circuito comercial, e imposibilitados por las carencias locales de toda "ostentación," no pudiendo establecer la diferencia entre "ricos" y "pobres" más que en la constricción al trabajo. ${ }^{41}$

La "novedad" residiría en el abandono de la tutela paterna y en las promesas que Garay les haría en cuanto a las ventajas de su nueva ubicación en la "puerta" de la tierra. No podía ser, en lo que reiteradamente se equivocan numerosos historiadores, ${ }^{42}$ la hipotética riqueza de una tierra que habían abandonado sus abuelos por inanición hacía sólo 40 años, ni su posible valorización productiva porque por un lado no hay nadie a quien venderle nada y por el otro con repartimientos de unos pocos indios por cabeza, ${ }^{43}$ que debemos comparar con los cientos que se "encomiendan" en fundaciones como la de Tucumán. ${ }^{44}$ Tan poco valor tiene la tierra en sí misma que las propias fundaciones se trasladan de un lugar a otro, como es el caso de Santa Fe, e incluso una suerte de estancia era cambiada por unos calzones usados en los primeros años de Buenos Aires. ${ }^{45}$

\footnotetext{
${ }^{40}$ Levene, Investigaciones, 178 señala que la mayoría de las ciudades nacientes fue poblada con "hijos de la tierra." Aporta el dato del pedido del contador Montalvo, en Asunción en el siglo XVI, solicitando que le envíen españoles, "porque de cinco partes las cuatro y media eran de criollos y estos dominaban por su número y aún por su espíritu" diciendo que "son amigos de cosas nuevas."

${ }^{41}$ Véase al respecto la interesante cita de Manuel Lizondo Borda, "El Tucumán de los siglos XVII y XVIII," en Historia de la nación argentina, 281: "con tales ejemplos (se refiere a sus padres encomenderos), algunos hijos de estos españoles principales y otros mozos pobres, especialmente mestizos -pues sus madres son indias-, no sólo son 'grandes holgazanes y vagamundos,' sino que despreocupándose de todo se andan por los pueblos indígenas, hechos 'a sus costumbres y modo de vivir' (según carta de Alonso de Ribera, gobernador, en 1608). Y estos criollos son en verdad nuestros primeros gauchos. Porque a ellos ya no les interesa el señorío, la riqueza ni España: sólo les atrae la vida fácil y ociosa de los campos en medio de los indios y junto a las indias."

${ }^{42}$ Por ejemplo De Gandia, "La segunda fundación," 206, dice que los segundos fundadores de Buenos Aires no iban con ilusiones de riquezas fabulosas sino a "regar las hortalizas con el sudor de su frente."

${ }^{43}$ En la recién fundada Santa Fe, los indios son 123 en total y están repartidos en 14 encomiendas, teniendo sólo la de Vera Mujica 42 (Groussac, Mendoza y Garay, 2:163, 314). Por otra parte, dada la índole de las poblaciones locales estas encomiendas eran más teóricas que reales.

${ }^{44}$ Hacia 1583, la cabeza de la gobernación de Tucumán, tiene 48 vecinos y 12,000 indios encomendados. Levene, Investigaciones, 193-4.

${ }^{45}$ Molina, primeras experiencias comerciales, 185 , cita en nota al pie a Trelles "Registro Estadístico de la Provincia de buenos Aires, t. I. año 1859" quien trae el dato del vecino Pedro Morán "que vendió sus tierras por unos calzones raídos y un coleto."
} 
Una vez establecida la "puerta" faltaba "abrirla" hacer real la circulación de mercancías y de plata por la misma. Hay que tener en cuenta que en el período que va hasta 1580 entraron sólo unos pocos barcos al Río de la Plata.

La salida, la clave de la supervivencia de Buenos Aires nuevamente amenazada por el hambre y el abandono, la proporcionará el genio y la tenacidad comercial del obispo de Tucumán Francisco de Vitoria quien, por razones que se originan en vínculos personales a nivel religioso, vínculos de parentesco $\mathrm{y}$, posiblemente, en conocimiento de antecedentes de algunas escasas comunicaciones establecidas con Asunción, promoverá (a su cuenta y riesgo) el comercio con los puertos del Brasil. ${ }^{46}$ Vinculando dos demandas crecientemente insatisfechas, metálico para dinamizar la economía brasileña, artefactos varios, azúcar y esclavos, para la producción minera, cerrará un circuito de cuya dinámica son testimonio, 300 años después, la inmensa supremacía de San Pablo y Buenos Aires sobre las urbes latinoamericanas. ${ }^{47}$

Lógicamente la plata del Potosí es el principal ingrediente de este circuito. La sangría de plata, alertada por el comercio limeño, recibirá inmediatamente la oposición de la

\footnotetext{
${ }^{46}$ Ver a este respecto los datos aportados por De Gandia, Historia de los piratas, 73-5, en que habla de parentescos y amistades entre tucumanos y brasileños. Es ilustrativa la descripción de la personalidad del obispo que se hace en la Copia de la carta del governador (Juan Ramirez de Velazco) de tucuman escrita al conde del villar virrey del Piru de 6 de abrill de 1587, sobre la nueva que se tuvo de los yngleses cosarios, documento 13, Historia de los piratas, 243: "con el se pasa harto trauajo que çierto es menester don de dios para lleuale su condiçion y sufrille su mala lengua que por no ofender los oydos de vuestra exçelençia no trato aquí algunas cosas solo suplico se de quenta a su magestad para que sea servido de sacalle de aquí y embie otro que se contente con la pobreza de la tierra y dexe de cargar nauios para enriqueçer a los enemigos que no a sido mal bocado el que lleuan agora que pasan de çien mill ducados y lo peor es que abran gustado para asegundar, por otras tengo escrito a vuestra exçelencia como enbio al brasil treyta mill pesos en plata y oro y por quintar para que vuestra exçelencia vea lo que se ha de haçer para cobrar los quintos porque aquí yo no veo de que echar mano y si no es con orden no conbiene hazer diligençia con el."

${ }^{47}$ Molina, primeras experiencias comerciales, 46, transcribe parte de la carta del comerciante portugués Francisco Suárez, escrita en 1596 en Río de Janeiro, Colección Hakluyt, 11:39: "Por aquí pasan cada tres o cuatro meses barcas de treinta o cuarenta toneladas cargadas de azúcar, arroz, tafetanes, sombreros y otros artículos de este país, que son llevadas por este río (de la Plata) en las dichas barcas y después de remontarles son conducidas al Perú. Y, a los cuatro o cinco meses las barcas bajan nuevamente este río cargadas con remesas de plata, pues aquellos lugares son todo riquezas... Este comercio que he visto desarrollar este año nos comunica con las minas de Potosí, que son las mejores y más ricas de todo el Perú." Agregando expresamente que los comerciantes peruanos iban a buscar mercancías a los puertos del Brasil, trayendo consigo "quince a veinte mil ducados en reales de plata u oro y los emplean aquí (Río de Janeiro) en mercancía y, cuando no la encuentran en esta ciudad, las buscan en Bahía o Pernambuco."
} 
monarquía española. Esta acababa de montar el sistema de flotas y galeones que pretendidamente aseguraba la contabilidad de los metales preciosos que se remitían desde América y por ende la recaudación fiscal sobre esos mismos metales. ${ }^{48}$ A su vez el sistema beneficiaba únicamente a los centros monopólicos de comercio, en particular a Sevilla (otra forma de asegurar los beneficios fiscales concentrando el cobro de alcabalas y privilegios en unos pocos lugares) con fuerte peso en el Consejo de Indias el que, por su parte, y como buena parte de la alta nobleza española depende también de las recaudaciones fiscales para acceder a sus prerrogativas.

Pese a los argumentos a favor de una salida más rápida y por lo tanto menos costosa que expusieron los intereses de Charcas y Potosí, la monarquía española no quiso nunca arriesgar en el difícil control de dos "puertas," e intentó mantener apenas entornada la que se le había abierto de par en par por Buenos Aires. Si la política no fue de clausura absoluta es porque era tan evidente que esta era la principal puerta de entrada a la riqueza platina, que si se la abandonaba definitivamente, podía caer en manos enemigas y con ella las riquezas del Perú. Argumento reiteradamente utilizado por la población bonaerense que incluso amenazó con abandonar el sitio si no se le otorgaban concesiones comerciales. ${ }^{49}$

Lo acontecido con Buenos Aires es un testimonio de que las leyes de la economía suelen primar por sobre las leyes políticas. Una vez establecida la ruta que desde Buenos Aires comunicaba con el Alto Perú, pasando por Córdoba (con derivaciones a Mendoza y Chile), Santiago del Estero, Tucumán y Salta, nunca dejó de ser, pese a las reiteradas prohibiciones de carácter absoluto, la principal vía de entrada y de salida de las mercancías de la región. ${ }^{50}$

Debemos detenernos en algunos aspectos del contexto de la época para poder volver a las modalidades cotidianas, a las prácticas culturales que se iban desarrollando, que son claves a la luz de su probable reflejo arqueológico.

En primer lugar debemos plantear un aspecto que estuvo en el centro de la vida colonial rioplatense que es el de la frontera entre lo lícito y lo ilícito. Cuando se refunda Buenos Aires y Francisco de Vitoria inicia su existencia comercial con la costa del Brasil, no

\footnotetext{
${ }^{48}$ Molina, primeras experiencias comerciales, $5,96$.

${ }^{49}$ Molina, primeras experiencias comerciales, 5, 41, 67, 96, 101 y especialmente 123.

${ }^{50}$ Ver nota 46, y Levene, Investigaciones, 69.
} 
sólo no hay ninguna prevención tomada en cuanto a este posible comercio (Ortiz de Zárate se había "obligado" en su capitulación a fundar dos puertos en la cuenca del Plata), sino que además el territorio del Brasil, como parte del reino de Portugal, se encuentra bajo el mando del monarca castellano. Son dos reinos distintos, pero tienen el mismo monarca, que debe velar por la felicidad de todos sus vasallos obrando en conveniencia de los mismos. Durante todo el período de unión de las dos monarquías a las presiones del Consejo de Indias castellano, abogando por el mantenimiento del monopolio comercial, se opondrán las del "Conselho Ultramarino" portugués, abogando por los intereses de plantadores y traficantes de las costas brasileñas y africanas.

Los monarcas castellanos serán siempre esencialmente castellanos (no por casualidad Portugal se enfrascará en una dura lucha de independencia) y promoverán medidas que, sin terminar con el comercio portugués, se inspiran tajantemente en el mantenimiento del monopolio comercial. Pero esa pequeña brecha, resultante de la imposibilidad de ahogar completamente el comercio portugués, permitirá que siga creciendo el torrente de plata que fluye por el Plata.

Por esta brecha se introduce también otro factor, trascendente en este panorama, como es el de la inmigración portuguesa. ${ }^{51}$ La realidad del comercio con Brasil pronto hace que los interesados lo tomen directamente en sus manos y, colocándose en una posición central (no olvidemos que el destino principal es Potosí) vengan a instalarse en Buenos Aires. De este modo la población porteña en sus primeras épocas es en un alto porcentaje población portuguesa (está en su sino que ambas tenga la raíz "puerto" en sus denominaciones). Presencia permanente, no sólo de comerciantes, sino también de artesanos de diversos oficios, durante todo este período, presencia a la que debemos ir sumándole la resultante de la acumulación de descendientes y de parientes productos de los matrimonios con las más destacadas hijas de los fundadores "mancebos de la tierra." Este aporte demográfico portugués se verá luego alimentado permanentemente por los desertores de la Colonia del Sacramento.

Es fundamental recordar esta base demográfica, y por tanto cultural, cuando tan esquemáticamente veamos planteada la oposición entre "españoles" de Buenos Aires y "portugueses" de Colonia del Sacramento.

\footnotetext{
${ }^{51}$ Ver nota 17.
} 
Cuando las "Reales Ordenes" y prohibiciones comerciales de todo tipo se hagan cada vez más imperiosas, la población de la cuenca del Plata y de Buenos Aires en particular se irá adaptando a actuar al margen de la legalidad, en el famoso "se obedece pero no se cumple." Afirmando su lealtad en todo tipo de escritos para luego "borrar con el codo lo que escribió con la mano."

Esa duplicidad, que andando en tiempo, se convertirá en corrupción desembozada de toda fuente de autoridad real que aterrice en estos pagos, está en la esencia de la historia colonial rioplatense y genera un gran problema heurístico a la hora de tratar con las fuentes documentales. Esto sin entrar a pensar en las consecuencias psico-culturales que esta práctica permanente generó, principalmente a nivel de las élites poderosas, entre quienes, probablemente, nadie confiara en nadie.

Esta situación se agrava particularmente a partir de 1640 cuando, separadas las dos monarquías y enfrentados militarmente ambos reinos, el comerciar con Portugal adquiere la categoría de traición a la patria.

La dinámica cotidiana de estos acontecimientos pone en acción, y en interrelación, diversas entidades culturales, grupos e incluso etnias, cuya forma de participación y de interesarse en los hechos es sin duda clave para entender esa gran resultante que fue la historia colonial rioplatense, pero de las cuales sólo logramos apercibir, lamentablemente, fragmentos aislados.

Un primer aspecto a destacar en este plano es el de la influencia lingüística, que de alguna manera es un "indicador" de ese complejo trasfondo cultural. Es significativo el desbalance entre el aporte Guaraní y el aporte Quechua al vocabulario rioplatense. El Guaraní es casi hegemónico en cuanto a la toponimia a la fauna y la flora. Es un territorio dominado por guaraníes o por guaranizados. Son seguramente las madres guaraníes las que enseñaron a sus hijos, "mancebos de la tierra," el ámbito en que tendrían que actuar. Sin embargo, el Quechua ocupa espacios claves en aspectos altamente significativos del lenguaje. En Quechua se identifica al padre "tata" y a la madre "mama," también se identifican los principales alimentos y, aspecto notable, es el vocabulario indígena relacionado con la actividad ganadera que se consolida en esta región.

Es un testimonio indudable del aporte demográfico andino entre los "mancebos de la tierra" que se instalarán en Buenos Aires. No hemos visto datos específicos al respecto, 
sabemos que la esposa de Ortiz de Zárate, como era habitual, era una "Ñusta" incaica y habría qué rastrear que parte de esta parentela participa en la apertura rioplatense.

Parece instalarse entonces, desde el principio, un doble aporte, por un lado andino ("quechuoide") y por otro asunceño ("guaranoide") en la naciente sociedad rioplatense. Este aporte quizás sea responsable de la rápida división en "partidos",52 entre los vecinos de Buenos Aires. Quizás un anticipo de esto haya sido el alzamiento de la población de Santa Fe contra Garay, inmediatamente después de fundada Buenos Aires. ${ }^{53}$ Esta oposición se puede haber manifestado también en los gobiernos de Hernandarias ${ }^{54}$ durante los cuales sospechamos que existía un "partido asunceño" -encabezado por Hernandarias- que intenta desplazar al partido "andino" o "andino-portugués" del control del comercio, legal y clandestino.

En este dibujarse de intereses con profundas raíces históricas y prehistóricas irán integrándose otros protagonistas que colaborarán a enriquecer la paleta con que se va pintando el desarrollo de la colonización rioplatense.

Desde el comienzo tenemos en escena a la población indígena ribereña los "guaraníes de las islas" y asimilables, mal que bien "encomendados" a la naciente colonia y eterna frontera con los indios "infieles," "Pampas," "Charrúas," "Guenoas" y "Minuanes,,"55 entre otras denominaciones, que cada vez adaptan más su accionar a las nuevas situaciones que se van creando en la cuenca del plata. Adaptación que pasa por el uso del caballo (que anula distancias y anteriores fronteras), por la introducción de la explotación ganadera, tanto para uso doméstico, como en el sentido de su participación en el comercio de cueros por el que reciben nuevos tipos de artefactos (de metal en particular) y nuevas prácticas culturales como el abuso del alcohol y las expediciones de saqueo, que introducen en el seno de los "infieles" las cautivas "cristianas" y su conocimiento del "otro," de la sociedad colonial.

\footnotetext{
${ }^{52}$ Molina, primeras experiencias comerciales, 177.

${ }^{53}$ Posiblemente por sentirse traicionados al haber perdido su condición de "puerta de la tierra" y las promesas que se vinculaban con ésta. Ver Groussac, Mendoza y Garay, 2:277, 304.

${ }^{54}$ Gobernó de 1591 a 1594 ; de 1600 a 1609 y de 1615 a 1618.

${ }^{55}$ Estos son probablemente el mismo grupo o grupos muy estrechamente emparentados.
} 
Muy pronto ${ }^{56}$ tendremos también en escena a los "guaraníes misioneros," distintos -y generalmente enfrentados- a los que sirvieron de base a la población de Asunción. Estos suman, pero no necesariamente mezclan, a los ingredientes prehistóricos, la problemática de la Compañía de Jesús, con sus propios intereses.

La expansión de estos generará nuevas fronteras, generalmente marcadas por una violenta oposición, con sus vecinos del oeste y en gran medida "connaturales" del núcleo colonizador instalado en Corrientes, ${ }^{57}$ con sus vecinos del sur -sus eternos enemigos- primero por nómades y luego por "infieles" y en guerra a muerte con sus vecinos del este-noreste los "mamelucos" paulistas, también instalados sobre la cuenca del Río de la Plata. ${ }^{58}$

Con estos introducimos un nuevo ingrediente, con su dinámica propia "brasileña" más que portuguesa. Los "paulistas" incentivados por la demanda "porteña" presionarán cada vez más sobre las reservas de mano de obra y de ganados de los territorios del sur y del sudeste. Su presencia -real o virtual- marcará permanentemente la colonización platense. $^{59}$

El tráfico comercial, principalmente de metales preciosos y de esclavos, atraerá a los "convidados de piedra" de las otras naciones en condiciones de surcar los mares, ingleses, franceses y holandeses. ${ }^{60}$ Aparecerán primero fundamentalmente como corsarios y luego cada vez más como comerciantes, generalmente del comercio "ilícito" aunque amparados por momentos en "asientos" ${ }^{61}$ contratados con la corona de Castilla. $\mathrm{Su}$ impronta cultural es difícil de rastrear $^{62}$ aunque son previsibles algunas consecuencias que se derivan de su presencia.

\footnotetext{
${ }^{56}$ El período fundacional se concentra entre 1607 y 1630. Ver Guillermo Furlong Cardiff, S.J., "Las misiones jesuíticas," en Historia de la nación argentina.

${ }^{57}$ Ver Enrique M. Barba, Don Pedro de Cevallos Gobernador de Buenos Aires y Virrey del Río de la Plata, Biblioteca de Humanidades, no. 19 (La Plata, 1937), acerca de estos enfrentamientos durante las expediciones de Cevallos.

${ }^{58}$ Las principales bandeiras contra las Misiones se dan entre 1627 y 1631, período en el que habrían secuestrado unos 60,000 indios. Ver Furlong, "Las misiones jesuíticas," 418.

${ }^{59}$ Por ejemplo, durante el apogeo de las bandeiras mencionado en la nota anterior, los paulistas teóricamente- son súbditos del rey de Castilla. En numerosas ocasiones la población actúa con criterio independiente a las órdenes reales.

${ }^{60}$ Ver el comentario de la nota 46 "abran gustado para asegundar."

${ }^{61}$ Molina, primeras experiencias comerciales, 65.

${ }^{62}$ Quizás no en el plano arqueológico donde sus artefactos son posiblemente identificables.
} 
Es el caso de su relación con los indios "infieles" quienes los ayudan a obtener cueros en las expediciones de corambre y que de esta manera se vuelven cada vez más dependientes de los productos "europeos," aunque, seguramente, también aquí, lo más trascendental sea la actitud mental adoptada por la población platense frente al problema de los corsarios. Estos representan sin duda un peligro real como lo atestigua el asalto de diversas ciudades portuarias, pero son también potenciales clientes. ${ }^{63}$ Estos servirán de argumento principal para justificar el mantenimiento del puerto de Buenos Aires, como vigía de los corsarios que se dirigen hacia el pacífico y, fundamentalmente, para justificar el arribo de las embarcaciones portuguesas "de aviso," las que, cargadas de esclavos que serán obligatoriamente "decomisados," tienen la gentileza de avisar la presencia de embarcaciones enemigas en las proximidades.

En la interacción de estos elementos, extracción de plata, introducción de esclavos y mercaderías brasileñas, aportes demográficos varios, "arribadas forzosas",64 y "navíos de aviso," agudización de las prohibiciones reales, ${ }^{65}$ injerencias de nuevos centros colonizadores como las Misiones y Saõ Paulo, oposiciones entre "partidos," gobiernos más o menos parciales pero siempre corruptos a la luz de la legalidad vigente, etc., transcurren los primeros 60 años de colonización del Río de la Plata hasta 1640. A partir de este año la situación se complica generándose una verdadera impasse que se intentará salvar con la fundación de Colonia del Sacramento en 1680.

Estos 40 años están marcados por las dificultades que se presentan para mantener el tráfico comercial con Brasil, el que, como no debemos olvidar, se hace esencialmente en embarcaciones portuguesas. Es en primer lugar la guerra de independencia de Portugal que se prolongará hasta 1678 y que -teóricamente para el Río de la Plata- hace del portugués un enemigo. Es también la invasión holandesa al noreste del Brasil y los esfuerzos que debieron volcarse en su expulsión.

\footnotetext{
${ }^{63}$ En 1661, en plena prohibición comercial Ascarate du Biscay observa 22 naves holandesas en el puerto de Buenos Aires. Levene, Investigaciones, 233-4.

${ }^{64}$ Las "arribadas forzosas," como su nombre lo indica, justificaban la entrada al puerto por contingencias de la navegación, al igual que en el caso de los "navíos de aviso" (mecanismo que se usa cuando el rey prohibe expresamente las primeras), la mercadería -generalmente esclavos- es decomisada y vendida en pública almoneda, donde el único ofertante es el propio armador. Al gobernador, como denunciante, le toca 1/3 del valor del remate. Ver Molina, primeras experiencias comerciales, 146, 148, 220.

65 Incluso se llega a instalar una "aduana seca" en Córdoba en 1623.
} 
Muchos indicios nos indican que la actividad, si bien reducida, no se detuvo totalmente. ${ }^{66}$ Probablemente los portugueses fueron en parte substituidos por comerciantes de otras nacionalidades, incluso españoles, y es interesante destacar que es en este período en que la península e isla de San Gabriel, donde será luego fundada la Colonia del Sacramento, comienza a utilizarse como punto de abastecimiento del comercio clandestino. Agotada la posibilidad de los "navíos de aviso," puesto que ahora pertenecen a una nación enemiga, estos llegan hasta San Gabriel a dónde va a surtirse la interminable bodega del "patache" que acompaña a los dos "navíos de registro" españoles autorizados anualmente. ${ }^{67}$

\section{La fundación de la Colonia del Sacramento y la invención de la "frontera"}

Entramos ahora específicamente en la colonización del actual territorio uruguayo, la "banda norte" del río de La Plata o la "banda oriental" del río Uruguay. ${ }^{68}$

Sobre el territorio uruguayo se realizaron algunos de los fracasados intentos de colonización del Río de la Plata, hasta que, desde el Perú, se "abrió la puerta" de Buenos Aires. Hasta la fundación de Buenos Aires la isla de San Gabriel fue uno de los principales puntos de recalada de los barcos que penetraban al estuario del Plata. Sobre la "banda norte" se desarrollarán también el intento fundacional de la expedición de Gaboto. ${ }^{69}$ Esta fracasa por las mismas causas que fracasará la expedición de Mendoza, esencialmente por no encontrar poblaciones indígenas susceptibles de tributar los mantenimientos imprescindibles. Se produce luego el fracasado intento de Ortiz de Zárate, ahora ya en la dinámica de la "apertura" de la tierra, pero que equivoca el emplazamiento, nuevamente en San Salvador, ${ }^{70}$ lejos de las principales bocas de salida del río Paraná.

\footnotetext{
${ }^{66}$ Torre, "La Colonia del Sacramento," 343-51, hace una síntesis de las actividades de los gobernadores porteños entre 1641 y 1678, aparecen todos implicados, de una manera u otra en el "comercio ilícito." Es interesante destacar que a partir de 1641 comienzan a ser rechazadas candidaturas a gobernador de Buenos Aires. El negocio ya no era tan bueno.

${ }^{67}$ Los pataches son embarcaciones de pequeño calado que acompañaban a los navíos de registro como un excedente que el monarca autorizaba para compensar el espacio ocupado por pasajeros y cargas reales que el armador estaba obligado a transportar. Ver Molina, primeras experiencias comerciales, 260, 261, 264.

${ }^{68}$ Creemos que es significativo que hasta el día de hoy el "Uruguay" no posea oficialmente nombre propio.

69 “San Salvador,” sobre el río Uruguay, que subsistió entre 1527 y 1529.

${ }^{70}$ Subsistió entre 1574 y 1576.
} 
A partir de 1607 comienza a desarrollarse la estrategia de las "reducciones," como forma de controlar la difícil frontera de los frentes de colonización de Asunción y Corrientes, estrategia que, directa e indirectamente, incidirá sobre el territorio de la "banda oriental." Por un lado se instalará en su territorio, en la boca del río Negro, el primer asentamiento permanente ${ }^{71}$ con la reducción de indios "Chanás y Charrúas" de Santo Domingo de Soriano. Por el otro, con la fundación de la reducción misionera de Yapeyú, y el descubrimiento de la "vaquería del mar," los territorios del norte del río Negro serán considerados como parte de la estancia de Yapeyú y, tanto estos como los del sur, serán el escenario de frecuentes "entradas" para la captura de ganados salvajes.

Los otros visitantes de la "banda norte" serán cada vez más los "accioneros," los abastecedores designados por el cabildo de Buenos Aires y los "corambreros" de distintos orígenes, americanos y extranjeros, a medida que el cuero se vaya transformando en una mercancía demandada.

Salvo por la población indígena autóctona, presionada cada vez más desde el oeste por las incursiones ecuestres de los Charrúas de la mesopotamia argentina y, desde el este y norte por las bandeiras paulistas, los demás se limitan a "entradas," visitas esporádicas que mantienen el carácter de "tierra de nadie" para este territorio. En ese contexto comienza a generarse un nuevo ingrediente humano, los "vagamundos," los futuros gauchos, desertores de todas las vertientes demográfico-culturales, asociado, en función de las circunstancias, con unas u otras. ${ }^{72}$

La Banda Oriental es entonces "tierra de nadie", 73 en realidad "frontera de todos," donde se encuentran los chanás reducidos, los guaraníes misioneros, los "accioneros" y "corambreros" porteños, los "corambreros"-"contrabandistas" franceses, ingleses y holandeses, los comerciantes-contrabandistas-corambreros portugueses, los bandeirantes paulistas y los gauchos, desertores de todos ellos.

Es en ese contexto que se funda la Colonia del Sacramento. Esta se instala en la península de San Gabriel, no por inadvertencia como sostienen algunos ${ }^{74}$ sino por ser el paraje donde, desde hacía décadas, se concentraba el comercio clandestino con Buenos Aires.

\footnotetext{
${ }^{71}$ En realidad sufrió varios desplazamientos entre la isla del Vizcaíno en la boca del Río Negro y sobre ambas márgenes del Uruguay.

${ }^{72}$ Ver cita 41.

${ }^{73} \mathrm{Si}$ exceptuamos a los Guenoas-Minuanes.

${ }^{74}$ Ver por ejemplo Azarola, epopeya de Manuel Lobo, 30.
} 
La fundación de Colonia del Sacramento es el resultado de la recuperación política del reino de Portugal, el que, desde que está en condiciones de hacerlo, se propone restablecer el aprovisionamiento de plata que se obtenía, con pocas dificultades, hasta 1640, y que era de capital importancia para la economía del Brasil. ${ }^{75}$

Son claras las presiones de los intereses lesionados por la falta de Plata en el Conselho Ultramarino y también los pasos políticos que el rey de Portugal va dando en este sentido. Es probable que esa presión se haya manifestado asimismo desde la también perjudicada Buenos Aires, aunque no hemos visto ninguna referencia documental en este sentido, la que probablemente se encuentre en los archivos portugueses. Primero será la extensión de la diócesis de Río de Janeiro hasta el Río de la Plata y casi inmediatamente la concesión, también hasta allí, de una capitanía a Correa de Sá. ${ }^{76}$

Llama la atención cómo en la historiografía hispanoamericana se insiste en las "ambiciones territoriales" de la corte portuguesa y en la "expansión de la frontera sur del Brasil" como causas principales de esta fundación. Nadie parece sorprenderse de que la frontera sur de la colonización portuguesa se encuentre en aquella época apenas llegando a la isla de Santa Catalina, y sólo produce comentarios absurdos el hecho de que experimentados militares instalen una "cabecera de playa" para asegurar su expansión hacia el sur, en el punto más indefenso, frente a la base principal del enemigo. Es quizás la misma actitud mental que impide admitir que fue la salida clandestina de la plata el sine qua non de la colonización del Plata y no la promesa a futuro de la feracidad de sus tierras.

La historiografía brasileño-portuguesa no titubea en estas definiciones, señalando que el proceso de apropiación del territorio será una consecuencia -como parte del proceso de asegurar la permanencia de la Colonia- y no una causa de la fundación de la Colonia del Sacramento.

Es la extracción de plata que se produce por la Colonia del Sacramento, y no el territorio que domina, la que la vuelve casus belli en las negociaciones entre España y Portugal. Basta con el ejemplo del tratado de "permuta" (o de "Madrid") en que el minúsculo territorio coloniense, legalmente considerado como el que queda comprendido por el

\footnotetext{
${ }^{75}$ Ferrand de Almeida, “Colónia do Sacramento," 66.

${ }^{76}$ Ibid.
} 
alcance de una bala de cañón desde su baluarte más avanzado, es canjeado por las decenas de miles de kilómetros cuadrados del territorio, densamente poblado además, de las Misiones orientales del Uruguay. No puede ser tampoco que ese dominio insignificante sea el punto principal de todos los tratados entre España y Portugal, cualquiera sea el conflicto que los haya involucrado.

Fundada Colonia del Sacramento, la realidad platense se enriquece con nuevos matices que resultan de la interacción de los distintos actores mencionados en las actividades comerciales, bélicas, productivas y delictivas- que se generan en torno a la Colonia. Con Colonia del Sacramento se amplía la dinámica de "frontera" que ya tenía el territorio Oriental. A la "frontera del desierto" 77 se agrega ahora la frontera de la Colonia.

Es la práctica cotidiana de esta interacción, el "comportamiento arqueológico" de estos actores, el que estamos descubriendo en nuestras investigaciones. Las pautas históricas de este comportamiento se vuelven difíciles de establecer en un contexto en el que la abundancia de fronteras impiden la sujeción a reglas de comportamiento permanentes que no sean otras que las que impone la propia dinámica fronteriza.

¿Quién realizaba el descomunal comercio clandestino que era la base de la economía platense? Esta es una economía también "de nadie" ya que no tiene responsables que se identifiquen. ¿Por qué mecanismos se trasladan e intercambian plata y mercaderías? ¿Qué rol jugaban las nacientes estancias que rodeaban Colonia y que significan un contacto permanente entre la población civil porteña y la población civil portuguesa? ¿Qué rol jugaba el sistema de guardias castellanas encargado de la vigilancia de esta frontera? ¿Cuál es el arbitraje de precios, de los crecientemente demandados cueros, entre la demanda portuguesa, española, inglesa u otras? ¿Qué significa desde el punto de vista de la cohesión social de las Misiones las importantes oportunidades de trabajo que surgían para vaqueros y "changadores"?

Estas pocas preguntas indican las dificultades que se encuentran para precisar el contexto histórico cotidiano en que se depositarán los actuales vestigios arqueológicos.

\footnotetext{
${ }^{77}$ Desierto "verde," con abundantes alimentos, por otra parte.
} 
La fundación de Montevideo ${ }^{78}$ agregará una nueva "frontera" a las anteriores, la que en sus primeros tiempos seguramente tendrá un comportamiento similar al de las otras "guardias" encargadas de la vigilancia de Colonia. Comportamiento que, pensamos, se caracteriza por una indefinición permanente, en el que: "por un lado vigilo, por el otro amparo, por el otro escondo" en función de diversos intereses particulares. Llama la atención la presencia de pobladores portugueses desde los primeros años de Montevideo, así como la deserción masiva y el refugio en la Colonia de la población "castellana" cuando los requerimientos del gobierno se consideran excesivos. ${ }^{79}$

\section{Conclusiones}

Es nuestra más fuerte impresión, que la principal característica del proceso de colonización del actual territorio uruguayo, es la instalación y desarrollo del "arbitraje," como sistema de vida, y el amparo en las "fronteras," como estrategia. "Arbitraje," tanto en su sentido literal como en su acepción económica, ${ }^{80}$ entre aquellos aspectos que más me convienen. Trabajar, pelear, desertar, denunciar, adular, comerciar, contrabandear no tienen un signo claro, ni son contingentes, más que para unos pocos actores de este proceso. La mayoría, desde los gobernadores hasta los indios, tienen una "frontera" en la cual recogerse, una posibilidad de opción, entre participar o desertar, entre obedecer o faltar, entre mentir o decir la verdad. ¿Quién en el Río de la Plata va a juzgar a un gobernador corrupto? ¿Qué justicia va a alcanzar al criminal refugiado entre los "infieles"? ¿Qué impuestos se cobran a las mercaderías de contrabando?

Estas "fronteras" desdibujan los comportamientos y condicionan profundamente la psicología de los participantes. ¿Qué valores adoptar en un mundo en que señorean la impunidad y la injusticia? El mismo delito, en determinadas circunstancias, lleva al patíbulo o lleva al enriquecimiento y "honorabilidad" de sus ejecutores. Con naturalidad pasmosa se pasa de perseguido a perseguidor, de enemigo a aliado, de socio a delincuente, de vecino a desterrado.

Tentados nos vemos a relacionar la desidia y la indisciplina vernáculas, que caracterizan y han caracterizado a las poblaciones platenses, con estas profundas raíces coloniales.

\footnotetext{
${ }^{78}$ El proceso fundacional se inicia en 1724.

${ }^{79}$ Ver Luis Enrique Azarola Gil, Los orígenes de Montevideo, 1607-1749 (Buenos Aires: Facultad, 1933), 155.

${ }^{80}$ En esencia es el establecimiento de equivalencias entre distintos valores.
} 